\title{
Validation of an ultra-precision optical coordinate measuring machine for the measurement of free-form objects in industrial processes
}

\author{
K.Cross ${ }^{1, a}$ and M.Strickland ${ }^{1}$ \\ ${ }^{1}$ RedLux Ltd, Southampton SO53 4DQ (UK)
}

\begin{abstract}
With an increasing capability for manufacturing complex free-form objects, the requirements for metrology are steadily increasing both in terms of accuracy and in the speed and point-cloud density of the measurements. Until recently, Coordinate Measuring Machines (CMMs) were restricted to relatively simple geometries, often as a result of their relatively long measurement set-up and acquisition times and the impact of environmental variations over this period. This article introduces a new, three-dimensional, ultra-precision optical coordinate machine for the measurement of free-form components and goes on to describe how the authors are adapting an industry accepted, international standard (ISO 10360) to fit its unique measurement approach. It goes on to describe how the adoption of this standard has twin benefits: firstly, it provides a unified approach to calibration and validation of the new CMM with regards to accuracy, repeatability and reproducibility of form and roughness measurements; secondly, end-users gain confidence that the instrument's results can be compared 'like for like' with older metrics generated by traditional equipment, easing integration of the new technology into the production line.
\end{abstract}

\begin{abstract}
Résumé: Avec les progrès technologiques dans la fabrication des objets $3 \mathrm{D}$ de forme complexe, les exigences métrologiques croissent à la fois en terme de précision, de vitesse d'acquisition et de taille de nuage de points. Jusqu'à récemment les machines de métrologie CMM étaient limitées à la mesure de formes relativement simples notamment $\mathrm{du}$ fait du temps de mise en œuvre et d'acquisition et de l'impact résultant des variations environnementales. Cet article présente une nouvelle machine de métrologie 3D sans contact ultra-précise pour la mesure des objets de forme complexe. Les auteurs décrivent comment ils s'appuient sur le standard international ISO 10360 pour traiter les données de mesure. Cette approche a deux avantages. Elle fournit une approche unifiée de calibration et de validation d'une nouvelle machine CMM au regard de sa précision, répétabilité et reproductibilité des formes et rugosités. Les opérateurs sont en confiance par cette capacité à comparer les résultats obtenus avec des mesures faites par des moyens conventionnelles. Cela rend le process d'intégration de ce nouveau moyen plus simple et plus rapide sur la ligne de production.
\end{abstract}

\section{Introduction}

Manufacturing companies have been using Coordinate Measurement Machines (CMM) as a way of product verification since the 1960's [1]. These machines typically comprise of a touch probe which follows a pre-programmed path, probing out point measurements on the sample that can then be compared with key dimensions from the design specification. Figure 1 shows a typical Cartesian CMM layout.

The mechanical arrangement of a traditional CMM, coupled with the complexities of programming its tool-path, meant that measurement times were long even when gathering a relatively small number of sample points. Long measurement times leave the data prone to the influence of environmental changes, such as temperature, limiting the point density and number of features that could be inspected. Ultimately the number of parts that may be sampled from the production line is likely to be small in comparison to the batch size as a result of the set-up and measurement times.

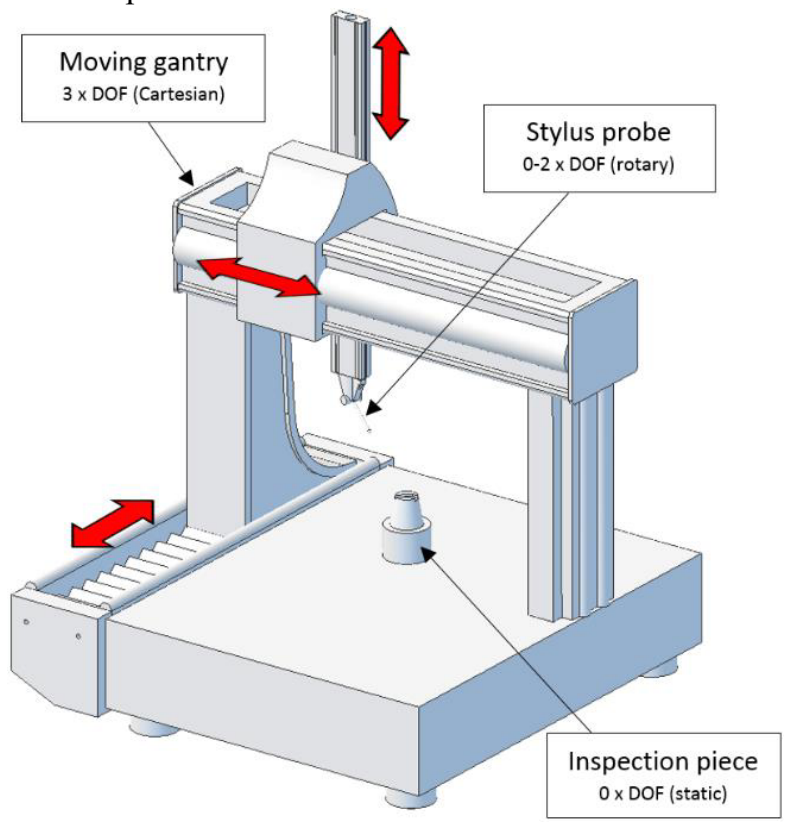

${ }^{a}$ Email de correspondance de l'auteur : gilles.duplessy@syhate.com 
Figure 1. Typical layout of a CMM showing its mechanical gantry and touch probe stylus

With the increasing complexity of manufactured parts it has become ever harder to program CMMs; furthermore the more detailed features of the parts being verified requires even longer measurement times exacerbating the effect of temperature fluctuations.

Some improvements to data density were achieved by continuous sampling of the probe's position as it traces a line on the sample, however, a new approach was required if metrology was to keep pace with manufacturing advances. This has led to the development of more sophisticated measurement devices, such as non-contact systems [2, 3] and multiaxis machines with more degrees of freedom. For instance, the 5-axis 'OmniLux' platform (figure 2). These machines deliver a step-increase in measurement speed and flexibility.

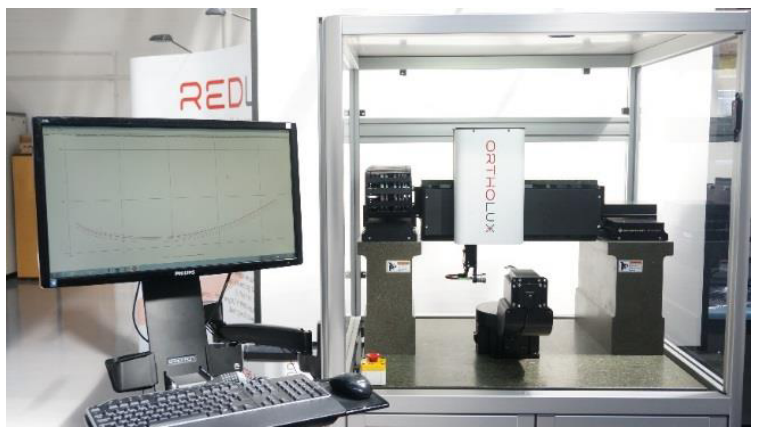

Figure 2. Measurement of an artificial knee using a 5-axis optical CMM.

The highly complex nature of a multi-axis instrument brings many difficulties, with axes alignment, and their inter-dependencies when moving, creating numerous challenging problems. In addition, any production lines adopting this new generation of instruments are sometimes left with a dilemma; their current inspection process has been geared towards data measured by traditional CMMs and in order to compare new and old inspection results they need the confidence that new and old are alike.

One solution to this is to design the calibration and verification procedures of the new instruments around the same standard used by the traditional CMMs, namely IS0 10360 [4], thus allowing a direct comparison of performance and repeatability on a 'like for like' basis. This article describes an approach to adapting this standard to fit non-Cartesian measurement systems.

\section{Mechanical Setup}

Inspection of a surface using a point-probe (be it contact or non-contact) requires the probe to be traversed in 3D space across the surface; in addition, the design of many probes places a constraint on the angle which the surface must be approached from (i.e. some sensors require inspection at an angle very close to the surface normal and most sensors have a physical fixturing which would lead to collision conditions at shallow angles of approach). This requires a minimum number of degrees of freedom (DOF) between the probe and the part under inspection.

The traditional approach of conventional CMMs has been to apply the necessary DOFs to the probe, and have the part fixed with respect to 'ground' (the machine base co-ordinate system). This is the mechanical configuration pre-supposed by the ISO 10360 standard for CMM verification and calibration.

There are certain advantages to this approach, especially if the part is large and cumbersome, however, in many cases it is more desirable for the DOFs to be divided between the probe and the part, with both moving with respect to ground. Often, it is desirable to achieve complete $360^{\circ}$ inspection of the part in a single pass (where repositioning and remeasuring would introduce unacceptable additional errors or datum inconsistencies). For roundness measurements, or any profiling of rotationally symmetric features, the ability to simply rotate the part can decrease measurement time by an order of magnitude, or better (table 1).

Table 1. Comparison of CMMs with static and mobile target parts.

\begin{tabular}{|c|c|}
\hline $\begin{array}{c}\text { Mobile sensor probe } \\
\text { Static target part }\end{array}$ & $\begin{array}{l}\text { Mobile sensor probe } \\
\text { Mobile target part }\end{array}$ \\
\hline $\begin{array}{l}\text { Well-suited to very large } \\
\text { and heavy parts }\end{array}$ & $\begin{array}{l}\text { Not suitable for very large } \\
\text { parts }\end{array}$ \\
\hline $\begin{array}{l}\text { Fixturing is very simple } \\
\text { (often the part can just } \\
\text { rest on machine base) }\end{array}$ & $\begin{array}{l}\text { Fixturing is more } \\
\text { complex; the part must be } \\
\text { well supported at all } \\
\text { angles }\end{array}$ \\
\hline $\begin{array}{l}\text { "Stacking" of axes results } \\
\text { in longer propagation } \\
\text { chain for errors }\end{array}$ & $\begin{array}{l}\text { Axes stack is split; error } \\
\text { propagation chain is } \\
\text { shorter on both sides }\end{array}$ \\
\hline $\begin{array}{l}\text { Cannot access top and } \\
\text { underside of part within a } \\
\text { single measurement }\end{array}$ & $\begin{array}{l}\text { Complete } 360^{\circ} \text { access of } \\
\text { the part is possible in a } \\
\text { single measuring session }\end{array}$ \\
\hline $\begin{array}{l}\text { Changing the probe angle } \\
\text { with respect to the part } \\
\text { surface normal requires } \\
\text { extensive Cartesian } \\
\text { repositioning }\end{array}$ & $\begin{array}{l}\text { The surface normal is } \\
\text { controlled by the part } \\
\text { orientation; the probe } \\
\text { does not need to } \\
\text { reposition as often }\end{array}$ \\
\hline $\begin{array}{l}\text { Measurements are slower, } \\
\text { due to the greater } \\
\text { distances which must be } \\
\text { traversed by the Cartesian } \\
\text { axes }\end{array}$ & $\begin{array}{l}\text { Faster for measurements } \\
\text { in general, and } \\
\text { rotationally symmetric } \\
\text { measurements in } \\
\text { particular }\end{array}$ \\
\hline
\end{tabular}


For this reason, some inspection platforms include one or more degrees of freedom on the part-side of the system, rather than the probe side. This may be a single rotary platform, a rotary and linear 2D table, or a combination of rotary DOFs.

\section{Translating the ISO Standard}

The optical CMM described in this paper is an example of such a system, where both part and probe have DOFs with respect to ground; this facilitates excellent measurement cycle-times well suited to the demanding requirements of high part-turnover typical of a production environment. However, it does mean that the machine deviates in a number of respects from the mechanical configuration envisaged by ISO 10360 .

This presents some important and interesting implications for demonstrating conformance with the ISO standard. In many ways, the optical CMM is a more capable and flexible platform than the ISO standard envisages. The system may be thought of as having two distinct articulation volumes, superimposed onto one another (figure 3).

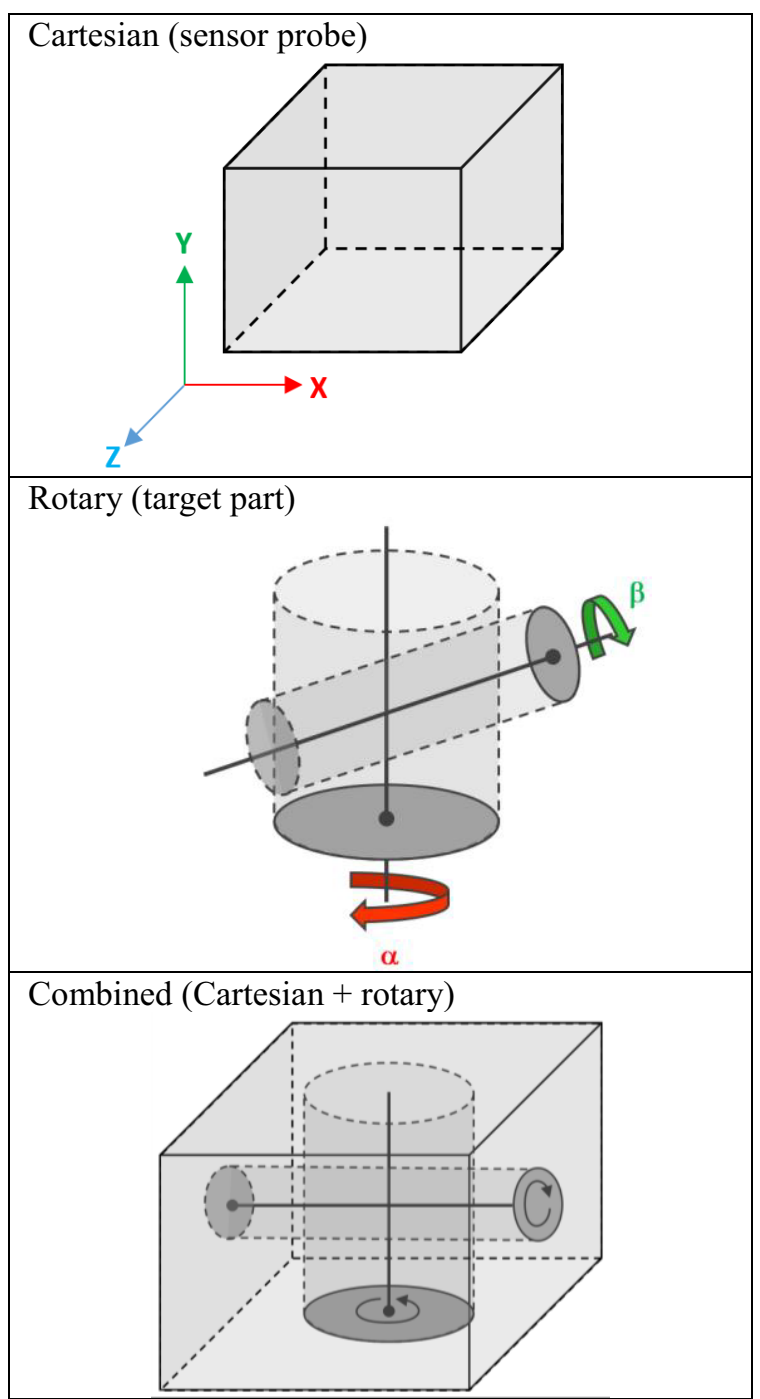

Figure 3: Combining DOFs on the probe-side and partside leads to an inspection volume which is more complex than the single Cartesian space envisaged by ISO 10360. 
To adopt the terminology of the ISO standard, this system features a 'translatory' (Tr) probe, with an 'articulating' (Art) target part:

-Probe (Tr): The conventional Cartesian volume, formed by the movement of the gantry. This is expressed in $\mathrm{x}, \mathrm{y}, \mathrm{z}$ co-ordinates and represented by a cuboid defining the range-of-motion limits (the basic measurement volume envisaged by ISO 10360).

-Target (Art): A secondary, non-Cartesian volume, formed by the movement loci of the two rotary axes; this volume is essentially in spherical co-ordinates, with the third rotary DOF constrained.

Such a system is capable of more sophisticated profiling than the basic provisions of the ISO standard imply, and whilst a simpler verification of the Cartesian probe measurement space would meet the basic requirements of the standard, it is of course better to perform the most rigorous characterisation and calibration possible, even if this extends beyond the standards' current limitations.

To address this challenge, a rigorous methodology is required to characterise the true articulation envelope of the machine. Whilst the details of this characterisation are specific to the machine in question, there are a number of general principals which would be applicable to other comparable measurement systems.

\section{System Calibration}

The ISO standard provides basic specific tests for calibration and verification. These are used as a first stage in system verification.

Probing errors are measured using a standard test sphere, as usual. The test sphere is positioned close to the centre of the Cartesian inspection volume, and rotated to expose different surfaces for profiling, as shown in figure 4.

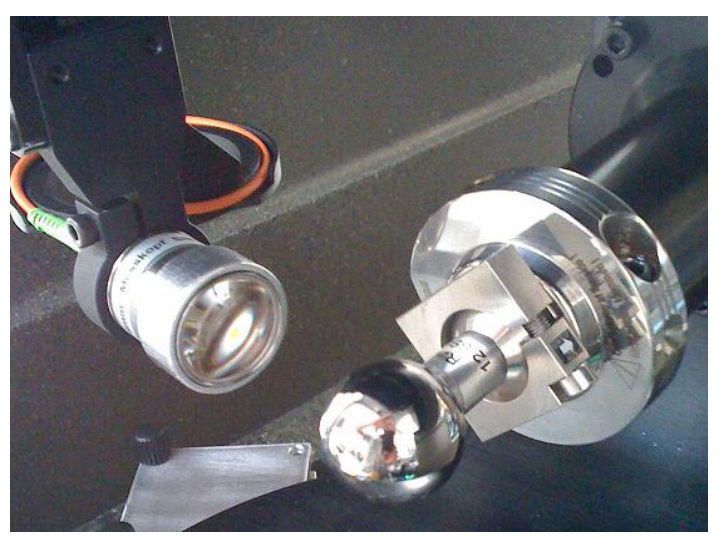

Figure 4: Probing errors via spheroid measurement.
This basic inspection provides useful information on the sensor probe calibration (figure 5) but does not give full information about the calibration of the overall system.

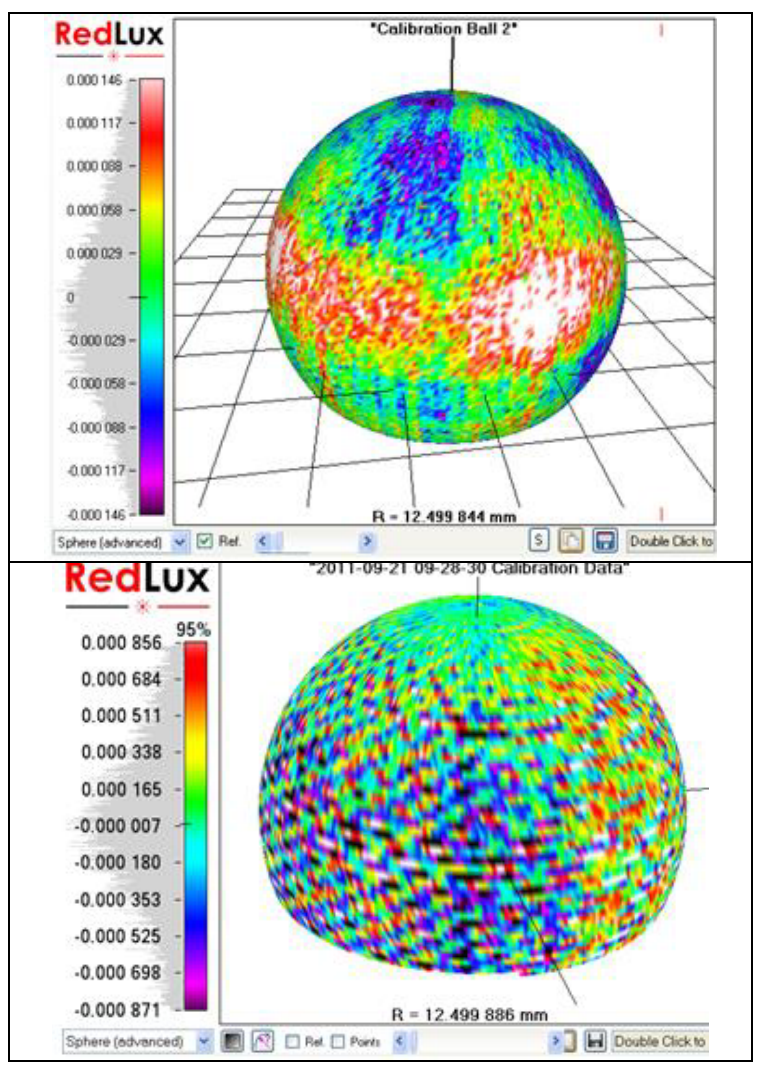

Figure 5: Calibration sphere measurement errors for optical CMM with air bearings (top) and mechanical bearings (below). Sphere is $\varnothing 25 \mathrm{~mm}$, grade $3(<80 \mathrm{~nm})$; $95 \%$ measurement variation is $\sim 150 \mathrm{~nm}$ (air), $\sim 870 \mathrm{~nm}$ (conventional). Comprehensive characterisation of the machine is ongoing, but these results are typical of achieved performance.

The standard length measurements in ISO 10360 are concerned with capturing variations across the Cartesian translatory volume of the probe. This is essentially independent of the target, and for the OmniLux can be performed as on a CMM, with a fixed target mounted either directly to the machine base (granite), or else mounted to the rotary assembly, but with the assembly locked. The probe orientation remains fixed relative to the machine co-ordinate system as the sensor traverses the target.

In reality, the rotary assembly volume must also be characterised, which is beyond the scope of ISO standard. To perform "length" measurement tests in this rotary axis system, a cage assembly was used to mount multiple gauge targets at pre-specified angles (figures $6 \& 7$ ). The cage is mounted to allow two rotations (around the mounting axis, and in the gauge block plane). By this means, the blocks are measured 
in multiple rotational positions. This test involves minimum movement of the probe on the Cartesian axis system; attention is focussed on the rotary axis assembly.

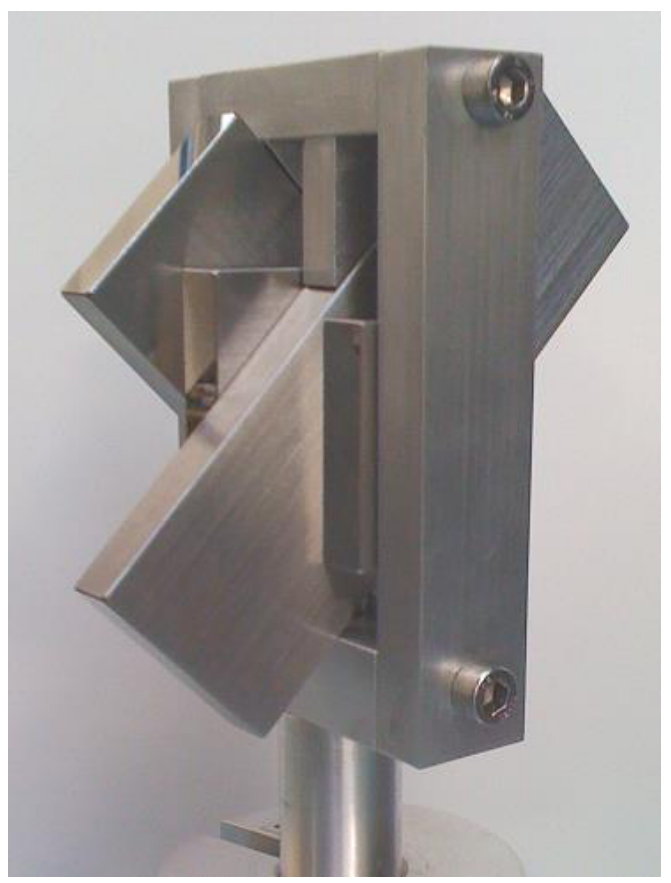

Figure 6: Gauge cage for rotary stage characterisation.

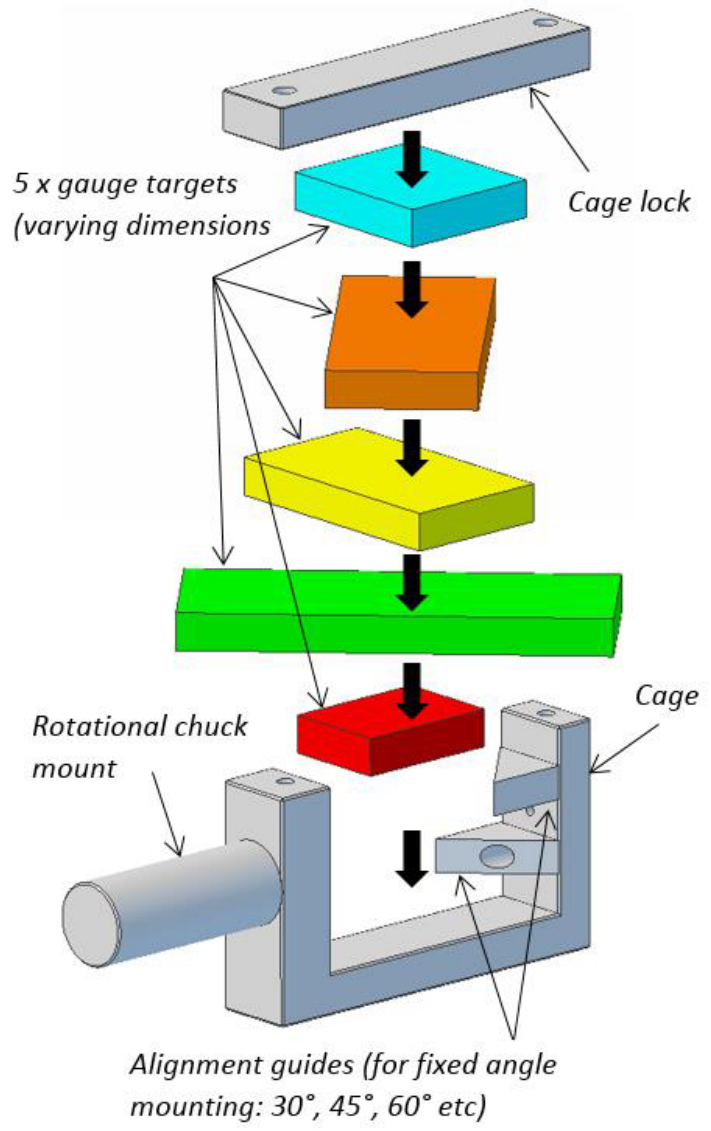

Figure 7: Gauge cage mechanical configuration.
The gauge cage pictured consists of five grade-1 calibration blocks of known and certified length. The nominal and certified length for each block along with the results of three system measurements are shown in table 2 .

Table 2: nominal length, certified centre-measured deviation and measured values $(\times 3)$ for gauge cage assembly measurement. For this test blocks marked '*' were inserted at a $45^{\circ}$ angle in the cage.

\begin{tabular}{|c|c|c|c|}
\hline $\begin{array}{l}\text { Gauge } \\
\text { Block }\end{array}$ & $\begin{array}{l}\mathrm{NL} \\
\text { Nominal } \\
\text { length } \\
(\mathrm{mm})\end{array}$ & $\begin{array}{l}\mathrm{CL} \\
\text { Certified } \\
\text { length } \\
(\mu \mathrm{m})\end{array}$ & $\begin{array}{l}\text { Measured } \\
\text { value }(\mu \mathrm{m}) \\
\text { difference } \\
\text { to } C L\end{array}$ \\
\hline \multirow{3}{*}{ 'A' } & \multirow{3}{*}{21.9} & \multirow{3}{*}{21.90013} & +0.61 \\
\hline & & & +0.79 \\
\hline & & & +0.54 \\
\hline \multirow{3}{*}{ ‘B'* } & \multirow{3}{*}{75} & \multirow{3}{*}{75.00023} & +1.65 \\
\hline & & & +0.06 \\
\hline & & & +1.12 \\
\hline \multirow{3}{*}{${ }^{\prime} C^{\prime}$} & \multirow{3}{*}{50} & \multirow{3}{*}{50.00011} & +0.42 \\
\hline & & & +1.30 \\
\hline & & & -0.21 \\
\hline \multirow{3}{*}{ ‘ $D^{\prime *}$} & \multirow{3}{*}{100} & \multirow{3}{*}{99.00078} & -1.33 \\
\hline & & & -0.36 \\
\hline & & & +0.02 \\
\hline \multirow{3}{*}{ ‘E' } & \multirow{3}{*}{25} & \multirow{3}{*}{25.00015} & +0.65 \\
\hline & & & +1.48 \\
\hline & & & -0.66 \\
\hline
\end{tabular}

In this results set, the largest difference between measured and certified values is $1.65 \mu \mathrm{m}$ for one of the blocks angled at $45^{\circ}$. Comprehensive characterisation of the machine is ongoing, but these results are typical of achieved performance.

\section{Further Work}

At present, a procedure has been used which independently verifies the Cartesian measurement volume (as per ISO 10360), and additionally the rotational measurement volume.

Ultimately, the intention is to include an additional verification test which combines these two measurement volumes in a single series of measurements. This will provide an additional level of confidence in the two earlier tests, and comprehensively demonstrate the performance of the overall inspection system as a single entity.

There are always a wide number of factors which may affect measurement results, including thermal effects, part deformation, control errors, signal noise, and 
system dynamics amongst many others. Work is ongoing to improve understanding of all of these factors for these measurement machines.

\section{Conclusions}

The additional verification procedures described in this overview provide the missing characterisation which the ISO standard alone fails to test. The ISO standard provides solid verification of the Cartesian space with the gauge-cage providing the missing verification of the rotary space for CMM systems with a mobile target part under inspection.

Ultimately, the lessons learned from developing new systems and the methods to calibrate and verify these systems should be fed back into the standards, to ensure that standards can keep pace with the constantly-moving technical field.

\section{References}

1. A. Weckenmann, G. Peggs, J. Hoffmann, "Probing systems for dimensional micro- and nano-metrology". Meas. Sci. Technol. 17 (2006), pp 504-509

2. C. Maul, M. Tuke, A. Taylor, A. Roques, "3D Linear and Volumetric Wear Measurement on artificial hip joints", Precision Engineering 34 (Oct 2010), pp $777-783$

3. RB. Cook, BJRF. Bolland, JA. Wharton, S. Tilley, JM. Latham, RJK. Wood, Pseudotumour Formation Due to Tribocorrosion at the Taper interface of Large Diameter Metal on Polymer Modular Total Hip Replacements, Journal of Arthroplasty (2013)

4. ISO 10360-8:2013, “Geometrical product specifications (GPS) - Acceptance and reverification tests for coordinate measuring systems (CMS) - Part 8: CMMs with optical distance sensors" 